\title{
616
}

\section{ファジィI-PD 予見コントローラを用いる倒立振子の位置制御の実験}

\section{A Design Method of Fuzzy I-P Servo System with Preview Actions}

\author{
○学 八巻 貴則（新潟大）学 王東（新潟大） \\ 正愛田一雄（新潟大） 今井 純一（新潟大）
}

Takanori Yamaki, Niigata University, Ikarashi, 2-nochō8050, Niigata, 950-2181

Wong Dong, Niigata University

Kazuo Aida, Niigata University

Junichi Imai, Niigata University

Key Words : Fuzzy Control, Preview Action, Inverted Pendulum

\section{1. 緒言}

現在,ファジィ制御は様々なところで実用化されている。 倒立振子においてもファジィ制御を適用した研究がなされ てきた。しかし，その多くは安定化制御を目的としたもの であり，位置制御への取り組みはあまり行われていない。

一方，目標軌道の未来情報を利用した予見制御を行うこ とで，制御エネルギーが減少し，追従性が向上することが 知られている。しかし，これまでファジィ制御に予見制御 を付加した研究はあまり進められていない。

そこで本研究では,ファジィ制御に北森 1)の I-PD 制御系 を導入したファジィ I-PD フィードバック制御系に, ファ ジィ予見要素を遗伝的アルゴリズム(以下 GA と表記)によ り最適化したファジィ予見制御系を付加し、ファジィI-PD 予見コントローラを設計する．実プラントとして，倒立振 子を使用し位置制御を行う。その実験結果から，本制御系 の有効性を検証し報告する。

\section{2. 制御対象モデル}

実験用制御対象として，倒立振子キット(Quanser Consulting Co, Ltd.）を用いる. 系の運動方程式は，次 式で示される。

$$
\begin{aligned}
& \left(m_{p}+m_{c}\right) m_{p} l_{p} \cos \theta \ddot{x}+m_{p} \ddot{\theta} l_{p}^{2}-m_{p} g l_{p} \sin \theta=0 \\
& \ddot{x}+m_{p} \ddot{\theta} l_{p} \cos \theta-m_{p} \dot{\theta}^{2} l_{p} \sin \theta=F
\end{aligned}
$$

$\theta$ を振子の角度， $x$ は台車の位置， $l_{p}$ は振子の重心ま での距離， $m_{p} ， m_{E}$ はそれぞれ振子と台車の質量を表して いる. また, $F$ は台車に加えられる力を表している.

(1)式より状態方程式は次のように表される.

$$
\left[\begin{array}{c}
\dot{x} \\
\dot{\theta} \\
\ddot{\boldsymbol{x}} \\
\ddot{\theta}
\end{array}\right]=\left[\begin{array}{cccc}
0 & 0 & 1 & 0 \\
0 & 0 & 0 & 1 \\
0 & -\frac{m_{p} g}{m_{c}} & 0 & 0 \\
0 \frac{\left(m_{p}+m_{c}\right) g}{m_{c} l_{p}} & 0 & 0
\end{array}\right]\left[\begin{array}{c}
x \\
\dot{\theta} \\
\dot{x} \\
\ddot{\theta}
\end{array}\right]+\left[\begin{array}{c}
0 \\
0 \\
\frac{1}{m_{c}} \\
-\frac{1}{m_{c} l_{p}}
\end{array}\right] F
$$

倒立振子の状態変数は位置, 角度, 速度, 角速度の 4 個あるが，本研究では位置制御を行うために位置以外の 状態を考慮しない。しかし、それでは倒立振子が不安定 になるおそれがあるので、最適レギュレータ理論を適用 し他の 3 個の状態を補償する. Fig. 1 のプラント部分は, これを含んだものとする.

\section{3. 制御系の構成}

Fig. 1 に本制御系のブロック図を示す.多入力から単入

カへの変換法によりファジィ制御規則数を減らす方法に， 北森の I-PD型モデルマッチング手法の設計公式を導入し ている.これにより, 3 つのスケーリングファクタ $s_{1}, s_{2}$, $s_{3}$ と，出力ゲイン $k_{f}$ をそれぞれ得ることができる ${ }^{1)}$ 。さ らに，予見制御部(Preview)を付加し，ファジィ I-PD 予 見制御系を設計する。

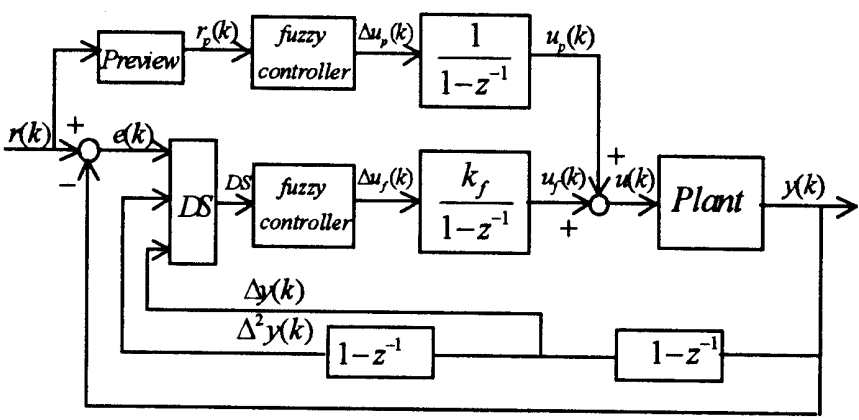

Fig. 1 Fuzzy I-PD preview control system

\section{4.多入力から単入力への変換法}

設計するファジィコントローラの制御規則言語は, Negative Big(NB), Negative Medium(NM), Negative Small(NS), Zero(ZO), Positive Small(PS), Positive Medium(PM)，Positive Big(PB)の 7 個あり，ファジィ コントローラへの入力数が $n$ 個の場合, 制御規則数は $7^{n}$ 個となる。もちろん，規則数が多ければ多いほど制御目 的は達成されやすいが，同じ制御性能が得られればパラ メータ調整，計算速度を考慮すると規則数が少ないほど よい。ここで，本研究で採用した単入力への変換法であ る Fig.1の DS 部分について説明する.

まず例として, 前件部変数を 2 個 $(e, \Delta e)$, 後件部変 数を 1 個とすると, 制御規則の関係は座標形式の Fig. 2 に示される.

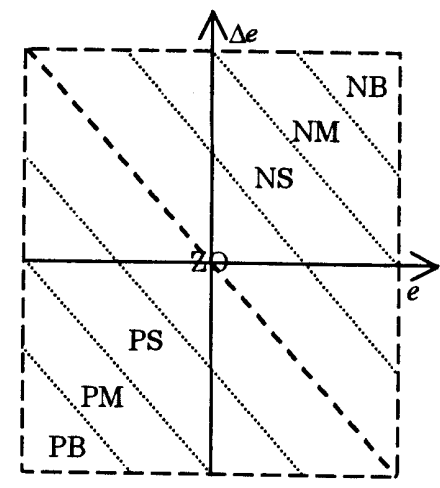

Fig. 2 The rule base of Fuzzy

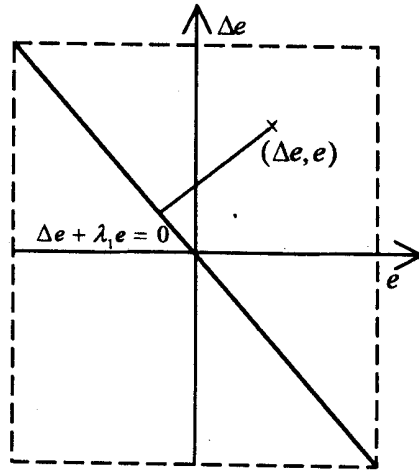

Fig .3 Distance of Fuzzy

日本機械学会 [No.027-1] 北陸信越支部 第39期総会・講演会論文集 ['02.3. 8, 石川県野々市町 $]$ 
これより,ファジィ言語の出力が ZO 直線からの距離に よって求められることが分かる。Fig.3に示すように ZO 直線を，傾きを $\lambda_{1}$ の直線 $\Delta e+\lambda_{1} e=0$ とする。また，任意 の点 $\times(\Delta e, e)$ と置くと, $\mathrm{ZO}$ 直線から点Xまでの距離は,

$$
D S=\frac{\Delta e+\lambda_{1} e}{\sqrt{1^{2}+\lambda_{1}^{2}}}
$$

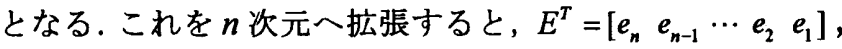
$\lambda=\left[\begin{array}{llll}1 & \lambda_{n-1} \cdots \lambda_{2} & \lambda_{1}\end{array}\right]$ より, 次式で示される.

$$
D S=\frac{\lambda E}{\sqrt{1+\lambda_{n-1}^{2}+\cdots+\lambda_{1}^{2}}}
$$

これより,ファジィコントローラは単入出力に変換でき る.

$$
\text { 5.メンバーシップ関数 }
$$

ファジィ集合のパラメータ調整の指針は，大きく分け るとメシバーシップ関数を等間隔に配置した均等配置，0 付近にファジィ集合を密にした内密配置，逆に外側を密 にした外密配置の 3 つがある.ここでいう0というのは， たとえば制御偏差 $e$ が 0 ということである.つまり内密配 置では，目標值付近で細かい制御を行うことを意味して おり，逆に外密配置では、目標值付近において不感帯に 近くなるという特性を持っている.

本研究では、前件部で上述の 3 タイプのメンバーシッ プ関数を適用する。また、後件部に関しては、均等配置 に固定している。

\section{6.予見制御部}

現在の目標值と未来の目標值の差の荷重平均を(5)式 に表す。これを予見情報として用い，ファジィ予見制御 を行う。

$$
r_{p}(k)=\frac{\sum_{i=1}^{L_{p}} W_{i}\{r(k+i)-r(k)\}}{\sum_{i=1}^{L_{p}} W_{i}}
$$

$r(k)$ は参照入力， $L_{p}$ は予見長さを表している．また， 重みW、を(6)式に示す。

$$
W_{i}=W_{0}^{i-1}
$$

ファジィ予見制御部において，後件部メンバーシップ 関数を変化させると, より効果が得られる.ここで, 後 件部のメンバーシップ関数の最適化と予見長さ $L_{p}$ を設 計する方法として GA を用いる.

GA は, 自然界の遺伝的な法則を工学的にモデル化し た最適化にすぐれた方法である。この GAのアルゴリズ ムには, 再生, 交叉, 突然変異の 3 つの基本的動作があ る。これらの動作を用い,(7)式の評価関数が最小となるよ うな予見入力を求める。

$$
J=\sum_{i=1}^{K}\left\{e^{2}(k)+\rho u^{2}(k)\right\}+\gamma O v
$$

Ovはオーバーシュート， $\rho, \Upsilon$ は重みを表す。

\section{7. 実跧}

上記の設計法を用い，倒立振子の位置を制御する実験 を行った. Fig. 5 はステップ幅 $20 \mathrm{~cm}$ の応答を表してい
る、また，本制御系の追従性を確かめるために参照入力 を(8)式に示すような 5 次曲線とした応答を Fig. 6 に示す.

$$
q(t)=a_{5} t^{5}+a_{4} t^{4}+a_{3} t^{3}+a_{2} t^{2}+a_{1} t^{1}+a_{0}
$$

$t$ は時間， $a_{0} \sim a_{5}$ は定数である.

また，両図の応答はメンバーシップ関数が均等配置の ものである。

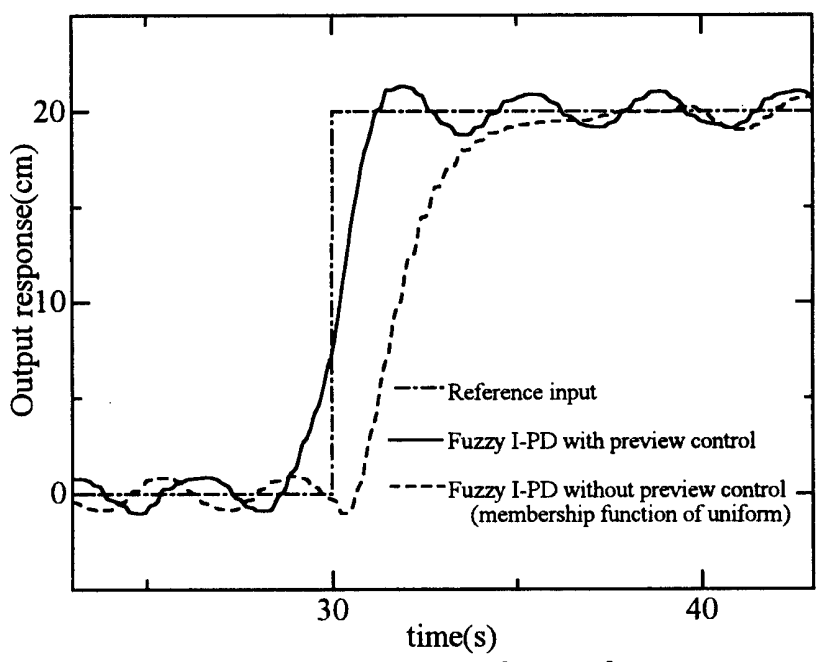

Fig. 5 Step responses of control system

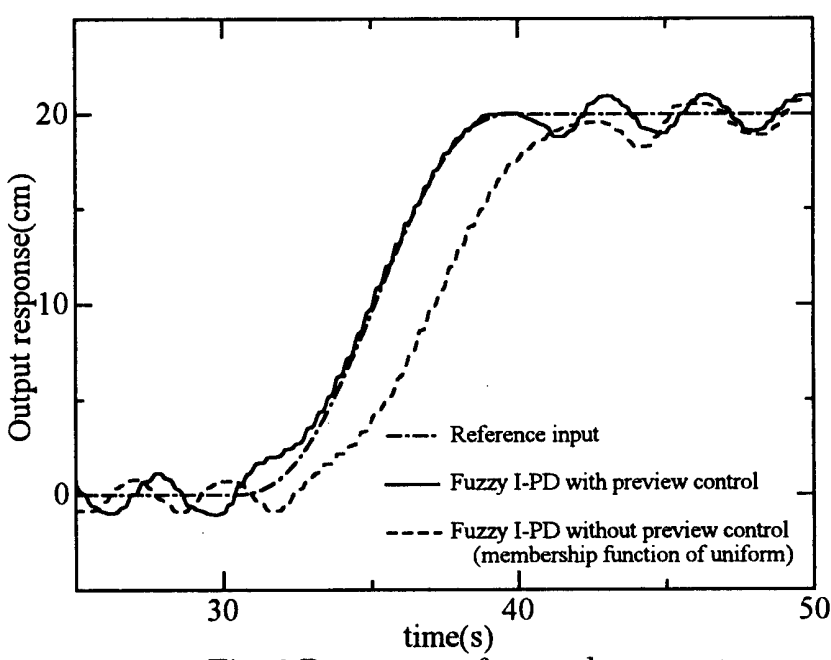

Fig. 6 Responses of control system to reference input eq. (8)

8、結言

ファジィ I-PD 予見コントローラを設計し．倒立振子 で位置制御の実験を行った。予見制御を付加することに より立ち上がり時間，制定時間を改善することができた。 また，追従性においても満足する結果が得られた. 今後 の課題として，最適レギュレータを用いずにファジィ I-PD コントローラでの，安定化制御と位置制御を行うこ とである。

\section{参考文 献}

1）北森, 制御対象の部分的知識に基づくサンプル值制 御系の設計法, 計測自動制御学会論文集, 15 巻, 5 号 (1979), 695-700

2) Dong Wang, Kazuo Aida, Research on Fuzzy I-PD Optimal Preview Control, Institute of Control Automation and Systems Engineers, Korea, (2000), $483-487$ 